\title{
TINJAUAN FIKIH MUAMALAH ATAS PRODUK JASA BERBASIS UJRAH (FEE BASED SERVICES) BANK KONVENSIONAL (SAMPEL PRODUK BANK MANDIRI DAN BCA)
}

\author{
Muhammad Nurul Alim ${ }^{1}$ \\ nurulalim.asy@gmail.com
}

\begin{abstract}
:
Review of Fikih Muamalah on Products of Conventional Bank's Fee-Based Services (Sample of Bank Mandiri and BCA Products). Although Islamic banks offer products of services which have the same kind and purpose as those are offered by conventional banks, most Moslems in Indonesia have not loyally make use all Islamic bank products for their financial transactions. Should the exercise of conventional bank's services' products be unavoidable, Moslems must be able to select and decide either the services are legal or illegal. This paper will study the fikih muamalah point of view on the conventional bank services that the customers will not fall in the usury transactions.
\end{abstract}

Keywords: conventional bank, Islamic bank, service product, usury transaction

\section{Abstrak:}

Tinjauan Fikih Muamalah Atas Produk Jasa Berbasis Ujrah (Fee Based Services) Pada Bank Konvensional (Sampel Produk Bank Mandiri Dan BCA). Meskipun bank syariah menawarkan jenis dan manfaat produk jasa yang sama dengan yang ditawarkan oleh bank konvensional, umat Islam di Indonesia belum sepenuhnya loyal untuk menggunakan segala produk bank syariah untuk transaksi keuangan mereka. Sekiranya penggunaan produk jasa bank konvensional tidak dapat dihindari, umat Islam harus dapat memilih dan memilah mana produk jasa yang halal dan mana yang haram. Paper ini mengkaji hukum fikih muamalah atas produk jasa bank konvensional agar pengguna jasa tidak terperosok ke dalam transaksi riba.

Kata kunci: bank konvensional, bank syariah, produk jasa, transaksi riba

\section{A. Pendahuluan}

Dunia usaha dan masyarakat umum sangat butuh terhadap jasa-jasa perbankan untuk menyelesaikan transaksi keuangannya. Transaksi yang umumnya dilakukan masyarakat di perbankan adalah menyimpan uang dan menariknya. Bagi kalangan pengusaha, transaksi perbankan yang dilakukan tidak sekedar menyimpan dan menarik

\footnotetext{
${ }^{1}$ Dosen Tetap Prodi Perbankan Syariah STAI Asy-Syukriyyah Tangerang
} 


\section{Jurnal Asy-Syukriyyah}

dana perusahaan. Inovasi produk-produk perbankan saat ini merupakan bukti beragamnya tuntutan dunia usaha atas jasa-jasa yang dapat ditawarkan oleh bank.

Bank Indonesia dalam seminar tanggal 16 Desember 2013 dengan tema "Era Baru Perbankan Syariah: Menuju Pengembangan Perbankan Syariah secara Cross Sector dan Terintegrasi" meluncurkan Outlook Perbankan Syariah 2014 yang menyebutkan bahwa market share bank syariah di posisi Oktober 2013 hanya mencapai 4,81\% ${ }^{2}$. Dan dalam Islamic Outlook 2015 yang dirilis oleh Karim Consulting disebutkan bahwa sampai Juli 2014 pangsa pasar perbankan syariah hanya mencapai 4,70\%. Dari data tersebut dapat disimpulkan bahwa masyarakat Indonesia yang penduduk muslimnya mencapai 87,18\% menurut hasil sensus $2010^{3}$ belum memberikan perhatian terhadap bank syariah sebagai bank untuk menyimpan dana dan menyelesaikan transaksi keuangan mereka. Memang miris namun bukan pesimis, mengingat perbankan syariah telah ada di Indonesia sejak 1991 yang ditandai dengan berdirinya Bank Muamalat. Ditambah lagi, eksistensi perbankan syariah telah diakui dengan dikeluarkannya Undang-Undang No. 21 tahun 2008 tentang Perbankan Syariah.

Sebagaimana dimaklumi, selain aktivitas funding dan financing, bank juga meluncurkan produk-produk jasa seperti money transfer, bank garansi, letter of credit, dll. Pendapatan jasa di bank syariah sangat berperan meningkatkan revenue terutama di saat menurunnya income karena persaingan dari kompetitor, khususnya konvensional ${ }^{4}$. Bank syariah yang kebanyakan produknya merupakan mirroring dari produk bank konvensional, menempatkan diri sebagai kompetitor bagi bank konvensional karena menyediakan produk sejenis. Selain besaran komisi/fee atas jasa produk menjadi pertimbangan nasabah untuk memutuskan apakah menggunakan bank syariah atau bank konvensional, dapat dipastikan ada pertimbangan lain yang menyebabkan umat Islam masih belum maksimal menggunakan produk jasa bank syariah.

Terlepas dari masih lemahnya keberpihakan umat Islam terhadap bank syariah, penulis menilai perlunya mengkaji apakah menggunakan produk jasa bank kovensional mubah atau haram bila ditinjau dari akad-akad yang ada dalam fikih muamalah.

\footnotetext{
${ }^{2}$ http://www.bi.go.id/id/ruang-media/siaran-pers/Pages/sp_155313_dkom.aspx (diakses 2 Oktober 2018).

${ }^{3} \mathrm{http}: / /$ id.wikipedia.org/wiki/Agama_di_Indonesia (diakses 2 Oktober 2018)

${ }^{4}$ Isa, Siti Sarah Mat; Ma'in, Masturah; Hanif, Azlina. Islamic Bank's Fee Income and Risk: Evidence from Malaysia. (Selangor Malaysia:Universiti Teknologi MARA(UiTM), 2016.
} 


\section{Jurnal Asy-Syukriyyah}

Penggunaan produk jasa bank konvensional oleh umat Islam tidak dapat dihindari dengan berbagai alasan, antara lain:

1. Bank syariah tidak menyediakan produk yang diinginkan nasabah yang mana di saat yang sama produk tersebut disediakan oleh bank konvensional. Layanan jasa tersebut tidak disediakan bank syariah karena adanya hambatan di luar hukum fikih seperti reputasi bank dan hubungan koresponden yang belum luas dengan bank luar negeri.

2. Alasan sederhana dari pengguna jasa seperti lokasi bisnis atau rumah lebih dekat ke bank konvensional, pelayanan lebih cepat dan nyaman, tarif layanan lebih murah dibandingkan dengan bank syariah, dll.

3. Minimnya edukasi dan sosialisasi kepada masyarakat yang dilakukan oleh bank syariah atas produk jasa yang dimilikinya.

4. Ketidaktahuan, kurangnya keberpihakan dan dukungan kaum muslimin atas gerakan ekonomi syariah melalui penggunaan lembaga keuangan syariah.

5. Keterikatan nasabah dengan tempat kerja atau mitra bisnis yang mengharuskan menggunakan bank konvensional.

Keadaan yang disebut di atas memaksa nasabah muslim tidak bisa menghindari bank konvensional. seyogyanya tidak membuat umat Islam mengabaikan bank syariah.

Karena produk jasa bank konvensional masih digunakan, dalam paper ini penulis melakukan kajian fikih muamalah untuk menjawab permasalahan berikut:

1. Bagaimana tinjauan fikih muamalah atas produk jasa bank konvensional?

2. Bila penetapan ujrah menurut Fatwa DSN MUI dipenuhi oleh bank konvensional, apakah dibolehkan bertransaksi jasa di bank konvensional?

Penelitian ini menggunakan pendekatan analisis kualitatif deskriptif. Data yang digunakan adalah produk dari bank konvensional yaitu Bank Mandiri dan Bank BCA yang diunduh dari situs resmi yaitu https://www.bankmandiri.co.id/ dan https://www.bca.co.id/. Peneliti melakukan analisis komparatif dengan meneliti karakteristik produk serta cara pembebanan fee yang dikenakan, lalu membandingkannya dengan kaidah-kaidah transaksi dalam fikih muamalah dan fatwa DSN MUI atas produk jasa tersebut.

Adapun tujuan penulisan paper ini tidak dimaksudkan untuk mendukung umat Islam menggunakan produk jasa di bank konvensional. Hanya saja dalam keadaan darurat dan mendesak, umat Islam perlu mengetahui produk-produk perbankan konvensional yang mana yang masih dibolehkan. Tujuan penulisan paper ini lebih spesifik lagi yaitu adalah 
untuk mengkaji produk jasa di bank konvesional dalam tinjauan fikik muamalah khususnya dalam timbangan Fatwa DSN MUI tentang ujrah pada jasa-jasa perbankan. Diharapkan paper inin memberikan kontribusi kepada para pembaca, khususnya kaum muslimin, agar dapat mengindentifikasi kehalalan produk jasa berbasis fee/komisi/ujrah di bank konvensional dari sudut pandang fikih muamalah.

\section{B. Landasan Teori}

Agar dapat menetapkan hukum fikih atas produk jasa di bank konvensional, penulis merasa perlu untuk mencantumkan literature yang berkaitan dengan larangan-larangan yang harus dihindarkan dalam bertransaksi dalam bertransaksi dan fatwa DSN MUI yang berkaitan dengan produk jasa di bank syariah.

\section{Larangan-Larangan Dalam Transaksi Keuangan}

Dalam literatur fikih muamalah, terdapat banyak larangan yang harus dihindarkan dalam bertransaksi, di antaranya: riba, maisir, gharar, tadlis, ba'i najasy, ihtikar, iktinaz, talaqqi rukban, dll. Di antara larangan tersebut, ada 3 larangan yang paling sering terjadi dalam transaksi perbankan yaitu riba, maisir dan gharar. Berikut ini uraian singkat mengenai ketiga larangan tersebut.

\section{Riba}

Secara etimologis, riba berarti ziyadah (tambahan), tumbuh, membesar. Secara terminologis, riba yaitu pengambilan tambahan dari pokok atau modal secara tidak baik atau bertentangan dengan prinsip syariah ${ }^{5}$. Riba yang dipraktekan pada masa jahiliyah, dapat dibagi 2 yaitu riba utang piutang dan riba jual beli. Kelompok pertama terbagi lagi menjadi riba qardh dan riba jahiliyah. Adapun riba jual beli terbagi menjadi riba fadhl dan riba nasi' $a h^{6}$. Penjelasan singkatnya sebagai berikut:

a. Riba qardh adalah riba peminjaman yang mana dalam akadnya disebutkan bahwa pihak yang meminjamkan menuntut pengembalian lebih kepada pihak meminjam.

b. Riba jahiliyah adalah utang yang dibayar melebihi dari pokok pinjaman karena peminjam tidak mampu mengembalikan pinjaman pada waktu jatuh tempo.

\footnotetext{
${ }^{5}$ Mardani, Fikih Ekonomi Syariah, (Jakarta: Penerbit Kencana Prenadamedia Group, 2012), hlm. 20.

${ }^{6}$ Ibid, hlm. 23.
} 
Ketidakmampuan ini dimanfaatkan pemberi pinjaman untuk mengambil keuntungan.

c. Riba fadhl yaitu riba akibat pertukaran barang sejenis yang tidak memenuhi kriteria secara kualitas (mitslan bi mitslin), kuantitas (sawaa an bi sawaa in), penyerahan (yadan bi yadin) sehingga menimbulkan ketidakjelasan (gharar) di antara kedua pihak.

d. Riba nasi'ah atau riba duyun, yaitu riba yang timbul akibat penangguhan penyerahan atau penerimaan jenis barang ribawi yang dipertukarkan dengan jenis barang ribawi lainnya. Riba dalam nasi'ah muncul karena adanya perbedaan, perubahan, atau tambahan antara yang diserahkan saat ini dengan yang diserahkan kemudian. Di bank konvensional, riba nasi'ah ditemui dalam bunga kredit, bunga deposito dan bunga tabungan. Prosentase bunga kredit kepada nasabah ditentukan di awal transaksi berdasarkan dana yang diberikan, padahal bisnis nasabah belum tentu untung. Prosentase bunga tabungan dan deposito juga ditentukan di awal, padahal bank bisa jadi merugi dalam menyalurkan dana kepada debitur.

Agar mudah dipahami, pembagian riba digambarkan dalam bagan di bawah ini:

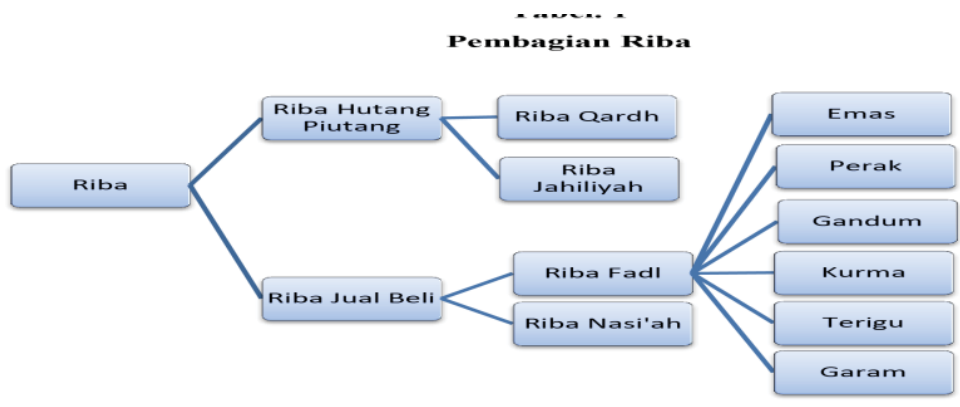

Sumber: Dilolah oleh Penulis dari berbagai sumber

Dalam Al-Quran, Allah tidak mengharamkan riba sekaligus tetap secara bertahap, yaitu:

1) QS Ar-Rum 30:39. Ayat ini tidak menunjukkan isyarat apapu mengenai pengharaman riba. Ayat ini menjelaskan kebencian Allah terhadap riba sekaligus peringatan supaya berhenti dari aktivitas riba. 


\section{Jurnal Asy-Syukriyyah}

2) QS An-Nisa 4: 160-161. Di tahapan ini Allah mengancam memberi balasan kerjas kepada orang Yahudi yang memakan riba. Riba digambarkan sebagai suatu yang buruk.

3) QS Ali Imran 3: 130. Riba diharamkan dengan dikaitkan kepada suatu tambahan yang berlipat ganda. Para ahli tafsir berpendapat bahwa pengambilan riba dengan tingkat yang cukup tinggi banyak dipraktekkan di masa tersebut.

4) QS Al-Baqarah 2: 278-279. Allah mengharamkan apapun jenis tambahan yang diambil dari pinjaman. Ayat ini me-nasakh semua ayat tentang riba sebelumnya dan riba telah diharamkan dalam segala bentuknya. Para ulama sepakat dengan keharaman riba, baik sedikit maupun banyak. Seseorang tidak boleh menguasai harta riba dan harus dikembalikan kepada pemiliknya jika diketahui. Ia hanya berhak atas pokok hartanya saja. $^{7}$ Ayat terakhir dengan jelas dan tegas menyebutkan apapun jenis tambahan yang diambil dari pinjaman adalah riba. Bila tidak meninggalkan riba, Allah dan RasulNya akan memerangi pelakunya.

Di transaksi perbankan, riba terdapat pada bunga bank yang diberikan oleh bank kepada nasabahnya, yaitu:

1. Bunga Simpanan, yaitu bunga yang diberikan sebagai balas jasa bagi nasabah yang menyimpan uangnya di bank. Contohnya adalah bunga tabungan dan bunga deposito.

2. Bunga Pinjaman, yaitu bunga yang dibebankan kepada nasabah oleh bank khusus untuk nasabah yang memiliki pinjaman di bank, contohnya adalah bunga kredit.

Kedua riba tersebut faktor utama pendapatan bank konvensional. Kedua macam bunga ini merupakan komponen utama faktor biaya dan pendapatan bagi bank konvensional. Baik bunga simpanan maupun bunga pinjaman saling mempengaruhi satu sama lainnya. Ketika bunga simpanan tinggi, maka secara otomatis bunga pinjaman ikut naik dan demikian pula sebaliknya.

\section{Maisir}

Maisir dapat diartikan sesuatu yng mengandung unsur perjudian (gambling) yang menempatkan salah satu pihak menanggung beban pihak yang lain. Setiap permainan atau pertandingan, baik yang berbentuk game of chance, game of skill ataupun natural event

\footnotetext{
${ }^{7}$ Azmatkhan, Shohibul Faroji. The Return of Dinar Dirham.(Jakarta: PT Khalifa Femark Nusantara, 2014). hlm 18.
} 
harus menghindari terjadinya zero sum game yakni kondisi yang menempatkan salah satu atau beberapa pemain harus menanggung beban pemain yang lain ${ }^{8}$. Allah SWT berfirman: "Hai orang-orang yang beriman, sesungguhnya (meminum) khamar, maisir, (berkorban untuk) berhala, mengundi nasib dengan panah, adalah perbuatan keji termasuk perbuatan syaitan. Maka jauhilah perbuatan-perbuatan itu agar kamu mendapat keberuntungan. Sesungguhnya syaitan itu bermaksud hendak menimbulkan permusuhan dan kebencian di antara kamu lantaran (meminum) khamar dan berjudi itu, dan menghalangi kamu dari mengingat Allah dan sembahyang; maka berhentilah kamu (dari mengerjakan pekerjaan itu)”. (QS. Al-Ma idah: 90-91).

\section{Gharar}

Gharar dapat diartikan sebagai ketidakpastian/ketidakjelasan atau spekulasi bagi kedua pihak yang bertransaksi (uncertainty to both parties) di mana terjadi incomplete information ${ }^{9}$. Gharar dapat terjadi dalam 4 hal, yaitu kuantitas, kualitas, harga dan waktu penyerahan. Di awal transaksi, kedua pihak sama-sama rela padahal keadaan masih tidak jelas bagi keduanya. Ketika terjadi ketidakjelasan di kemudian hari, salah satu pihak akan merasa terdzalimi.

\section{Ketentuan Ujrah Dalam Fatwa DSN MUI}

Hingga saat ini, DSN MUI telah mengeluarkan 102 fatwa yang berkaitan dengan muamalah maliyah. Fatwa-fatwa yang menurut pendapat penulis berkaitan dengan produk jasa berbasis ujrah adalah sebagai berikut:

1. Fatwa No. 09/DSN-MUI/IV/2000 Tentang Pembiayaan Ijarah.

2. Fatwa No. 10/DSN-MUI/IV/2000 Tentang Wakalah.

3. Fatwa No. 11/DSN-MUI/IV/2000 Tentang Kafalah.

4. Fatwa No. 12/DSN-MUI/IV/2000 Tentang Hawalah.

5. Fatwa No. 22/DSN-MUI/III/2002Tentang Safe Deposit Box.

6. Fatwa No. 24/DSN-MUI/III/2002Tentang Jual Beli Mata Uang (Al-Sharf).

7. Fatwa No. 34/DSN-MUI/IX/2002 Tentang Letter Of Credit (L/C) Impor Syari'ah.

8. Fatwa No. 35/DSN-MUI/IX/2002 Tentang Letter Of Credit (L/C) Ekspor Syari'ah.

9. Fatwa No. 42/DSN-MUI/V/2004 Tentang Syariah Charge Card.

\footnotetext{
${ }^{8}$ Ibid, hlm. 28.

${ }^{9}$ Ibid, hlm. 29.
} 
10. Fatwa No. 54/DSN-MUI/X/2006 Tentang Syariah Card.

11. Fatwa No. 57/DSN-MUI/V/2007 Tentang Letter Of Credit (L/C) Dengan Akad Kafalah Bil Ujrah.

12. Fatwa No. 58/DSN-MUI/V/2007 Tentang Hawalah Bil Ujrah.

Ketentuan tentang fee atau ujrah yang tercantum dalam fatwa-fatwa tersebut di atas dapat disimpulkan sebagai berikut:

1. Besarnya fee/komisi/ujrah disepakati dan diketahui jelas oleh kedua pihak di awal transaksi.

2. Besaran fee/komisi/ujrah tetap dan pasti dan di akad dinyatakan dalam bentuk nominal, bukan dalam bentuk prosentase yang dihitung dari pokok.

3. Pembayaran fee/komisi/ujrah dapat diambil dari dana nasabah sesuai kesepakatan dalam akad.

Ketentuan ujrah akan digunakan sebagai perbandingan atas pengenaan fee atau komisi atas jasa yang ditawarkan oleh bank konvensional.

\section{Produk Perbankan Konvensional}

Secara umum, produk perbankan dikelompokkan menjadi 3, yaitu: produk penghimpunan (funding), produk pembiayaan (financing) dan produk jasa (services).

\section{Produk Funding}

Funding di perbankan merupakan kegiatan penghimpunan dana dari masyarakat dengan menawarkan berbagai jenis simpanan. Secara umum, rekening simpanan dapat dikelompokkan menjadi 2, yaitu:

a. Rekening yang digunakan untuk bertransaksi (transactional accounts) berupa giro (current account) dan tabungan (saving account). Penamaan produk tabungan bisa saja berbeda di setiap bank, misalnya :

1) Tahapan BCA, Tahapan Xpresi, Tahapan Prestasi, Tahapan Gold, BCA Dollar. yang dilengkapi dengan kartu ATM Paspor BCA ${ }^{10}$.

2) Mandiri Tabungan dan Mandiri Giro ${ }^{11}$.

\footnotetext{
${ }^{10} \mathrm{https}: / /$ www.bca.co.id/id/Individu/Produk/Simpanan/Tahapan (diakses 5 Oktober 2018)

${ }^{11}$ https://www.bankmandiri.co.id/web/guest/simpanan-perseorangan (diakses 5 Oktober 2018)
} 
Secara umum, fasilitas tabungan dan giro adalah untuk menyimpan, menarik, menyetor dan mentransfer dana, membayar berbagai tagihan (kartu kredit, listrik, telepon, koran dan lain-lain) hingga sebagai alat pembayaran barang serta jasa.

b. Rekening yang digunakan sebagai simpanan tetap (fixed deposit accounts) yang pencairannya terikat dengan tanggal jatuh tempo simpanan berupa deposito berjangka waktu (time deposit), sertifikat deposito (certificate of deposit), money market account dan deposit on call ${ }^{12}$.

Penamaan produk dapat berbeda dari satu bank ke bank lainnya. Atas dana yang disimpan nasabah, bank menjanjikan imbalan jasa simpanan berupa bunga di awal akad pembukaan rekening. Tingkat suku bunga funding berfluktuatif mengikuti BI rate yang dapat berubah dari waktu ke waktu.

DSN MUI telah mengeluarkan fatwa No. 01 tentang Giro, fatwa No. 02 tentang Tabungan, dan fatwa No. 03 tentang Deposit yang menetapkan ketidaksesuaian ketiga produk tersebut dengan ketentuan syariah karena berdasarkan perhitungan bunga.

\section{Produk Financing}

Financing berkaitan dengan panyaluran dana bank kepada nasabah pembiayaan berupa kredit atau pinjaman. Di akad kredit disebutkan dengan jelas pokok dan bunga pinjaman yang berdasarkan tingkat suku bunga. Untuk mencegah terjadinya negative spread, bank menetapkan tingkat suku bunga financing di atas tingkat suku bunga funding. Ada beberapa cara pembebanan bunga, yaitu:

a. Sliding Rate, Pembebanan bunga setiap bulan dihitung dari sisa pinjamannya, sehingga jumlah bunga yang dibayar nasabah setiap bulan menurun seiring dengan turunnya pokok pinjaman.

b. Flat Rate, Pembebanan bunga setiap bulan tetap dari jumlah pinjamannya, demikian pula pokok pinjaman setiap bulan juga dibayar sama, sehingga cicilan setiap bulan sama sampai kredit tersebut lunas.

c. Floating Rate, Jenis ini membebankan bunga dikaitkan dengan bunga yang ada di pasar uang, sehingga bunga yang dibayar setiap bulan sangat tergantung dari bunga pasar uang pada bulan tersebut.

\footnotetext{
${ }^{12}$ https://www.bnisyariah.co.id/id-id/bisnis/treasuri/bnidepositooncallibhasanah (diakses 1 Oktober 2018)
} 


\section{Jurnal Asy-Syukriyyah}

Skema pembiayaan yang diberikan dapat berupa ${ }^{13}$ :

a) Fixed loan atau pinjaman tetap, misalnya kredit tanpa agunan (KTA).

b) Installment loan, yaitu pinjaman dengan agunan berupa barang yang pembeliannya dibiayai oleh pinjaman tersebut atau asset lain yang dimiliki oleh peminjam ${ }^{14}$. Contoh pinjaman ini yaitu kredit kendaraan bermotor, KPR, dsb.

c) Overdraft facilities, yaitu penarikan dana tabungan/giro melebihi saldo untuk mengatasi cash flow perusahaan jangka pendek, yang mana saldo negatif tersebut biasanya harus dipulihkan kembali dalam jangka waktu 1 bulan. Saldo negatif dihitung sebagai pinjaman dari bank.

d) Investment loan, yaitu pinjaman dengan bunga tetap untuk pembelian asset tetap seperti gedung, peralatan, mesin atau membiayai kegiatan pembangunan ${ }^{15}$.

e) Working capital loan, yaitu pinjaman jangka pendek untuk modal usaha ${ }^{16}$.

f) Consumer loan, yaitu pinjaman yang dapat digunakan untuk tujuan konsumtif apapun, biasanya berkaitan dengan pembelian barang tertentu.

\section{Produk Jasa Berbasis Fee (Fee Based Services)}

Produk-produk berbasis jasa (fee-based services) di bank konvensional secara umum dapat dikelompokkan menjadi:

a. Funding Related Services, yaitu produk jasa yang berkaitan dengan penghimpunan dana nasabah, misalnya money transfer/remittance, money collections, auto debit/standing instruction, debit card, dll.

b. Financing Related Services, yaitu produk jasa yang berkaitan dengan pembiayaan dan penyaluran kredit seperti bank garansi, Letter of credit, foreign exchange, credit card, dll.

Di pembahasan paper ini, karakteristik dari produk-produk jasa akan dijelaskan lebih rinci agar dapat dipahami bagaimana tinjauan hukum fikih muamalah atas produk tersebut. Bagan 2 berikut memperlihatkan pengelompokan produk bank konvensional.

\footnotetext{
${ }^{13}$ Zainul Arifin, slide mata kuliah Keuangan dan Perbankan Islam IEF Trisakti Jakarta, 2014.

${ }^{14} \mathrm{http} / / / \mathrm{www} \cdot$ businessdictionary.com/definition/installment-loan.html (diakses 1 Oktober 2018)

${ }^{15} \mathrm{http} / / / \mathrm{www}$. investorwords.com/15283/capital investment loan.html (diakses 1 Oktober 2018)

${ }_{16} \mathrm{http}: / /$ www.investorwords.com/5335/working capital loan.html (diakses 1 Oktober 2018)
} 


\section{Bagan 2}

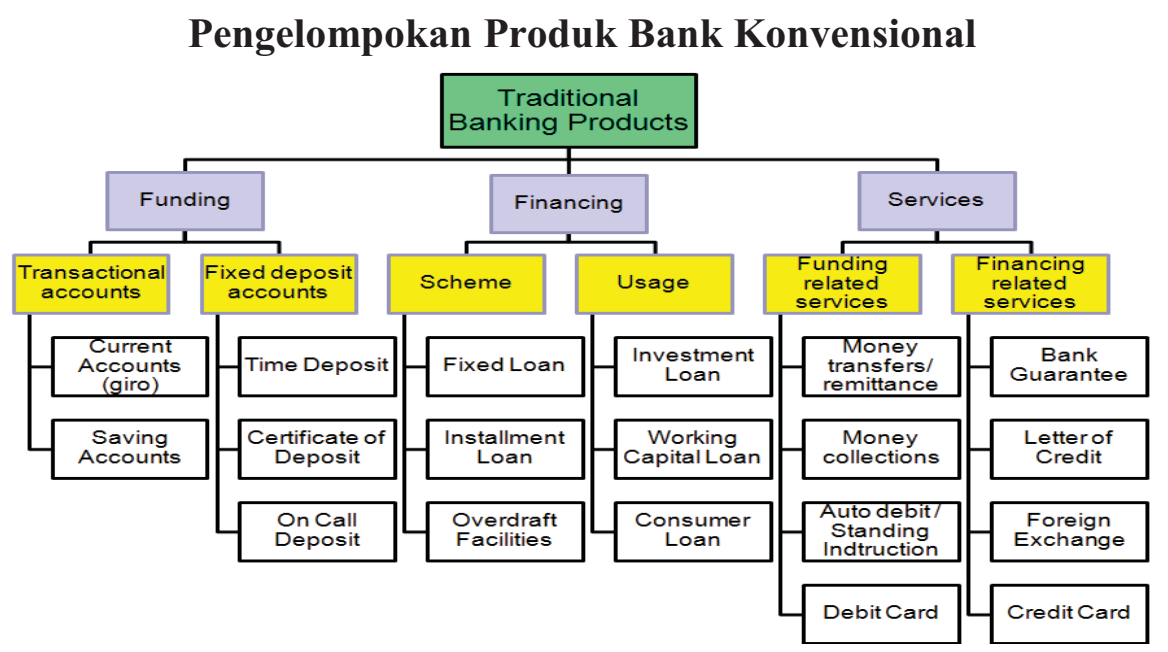

Sumber: Zainul Arifin, slide mata kuliah Keuangan dan Perbankan Islam IEF Trisakti Jakarta, 2014.

\section{Hasil Penelitian}

\section{Funding Related Services}

Funding related services merupakan produk jasa yang berkaitan dengan penghimpunan dana pihak ketiga atau nasabah oleh bank. Kesesuaian jasa yang berhubungan dengan penghimpunan dana pihak ketiga dengan fatwa DSN MUI akan dibahas berikut ini:

\section{Money Transfer}

Money transfer yaitu jasa pengiriman uang dalam valuta Rupiah ataupun valuta asing yang dilaksanakan atas permintaan dan untuk kepentingan nasabah ${ }^{17}$. Untuk transfer antar bank skala nasional, jenis transfer dapat berupa:

1. Kliring, dengan jangka waktu 1-2 hari kerja dengan biaya $\mathrm{Rp} 5.000,-$.

2. RTGS (real time gross settlement) dengan jangka waktu 1-3 jam dengan biaya berbeda untuk masing-masing bank, umunya dikenakan fee sebesar Rp 35.000,--

3. Transfer online melalui ATM antar rekening di satu bank atau ke bank lain, baik bank konvensional maupun bank syariah yang tergabung dalam jaringan ATM bersama dan

\footnotetext{
${ }^{17}$ https://www.bankmandiri.co.id/web/guest/tarif-layanan\#tarif-transfer (diakses 2 Oktober 2018)
} 


\section{Jurnal Asy-Syukriyyah}

ATM Prima/Link. Waktu transfer adalah realtime (seketika) dengan biaya Rp 5.000,per transaksi.

4. Transfer valas dapat dilakukan antar rekening di satu bank atau ke bank lain di dalam dan luar negeri. Bank Mandiri menetapkan komisi 1/8 \% (min USD 5 ; max USD 150) bila sumber dana sama dengan valuta yang ditransfer dan tanpa biaya bila sumber dana tidak sama dengan valuta yang ditransfer karena akan menggunakan kurs TT.

Di bank syariah, akad money transfer adalah wakalah, yaitu bank menjadi wakil nasabah untuk mentransfer dananya. Biaya transfer sebagai ujrah. Di bank konvensional, biaya transfer yang dibayar oleh nasabah dapat pula diangap ujrah. Komisi transfer valas dengan menerapkan prosentase $1 / 8 \%$ namun minimum komisi USD 5 dan maksimum USD 150, dapat dirinci sebagai berikut:

a. Bank menghitung bahwa beban operasional minimum untuk mengeksekusi transaksi adalah USD 5. Bank belum menutupi operasionalnya bila nasabah mentransfer kurang USD 4.000 sehingga komisi tetap USD 5. Hal ini dapat diterima secara fikih karena nilainya tetap dan disepakati.

b. Bank menetapkan biaya maksimum USD 150 karena beban operasional telah tertutupi dan bank mendapatkan fee yang layak. Dengan demikian, bila nasabah mentransfer lebih dari USD 120.000, fee transfer tetap USD 150. Dalam tinjauan fikih muamalah, hal ini dapat diterima karena nilainya tetap dan dapat disepakati.

c. Bila nasabah mentransfer dana antara USD 4.000 dan USD 120.000 maka berlaku perhitungan berdasarkan prosentase yang $1 / 8 \%$. Hal ini bertentangan dengan fatwa DSN. Dapat keluar dari syubhat ini maka angka fee yang dikenakan telah disebutkan dan disepakati di awal. Penggunaan jasa bank konvensional seyogyanya dilakukan bila tidak ada bank syariah yang memiliki hubungan koresponden dengan bank di luar negeri ke mana kita akan mentransfer dana.

\section{Money collection atau inkaso}

Money collection atau inkaso ${ }^{18}$, yaitu penagihan warkat bank lain di mana bank tertariknya berbeda wilayah kliring atau berada di luar negeri. Inkaso dalam negeri dapat berupa misalnya Wesel, Cek, Bilyet Giro, Cek Perjalanan, Promissory Notes (Promes), dll. Inkaso luar negeri biasanya berupa Bank Draft, Cheque, International Money Order.

\footnotetext{
${ }^{18} \mathrm{https} / / /$ www.bankmandiri.co.id/web/guest/tarif-layanan\#tarif-inkaso (diakses 2 Oktober 2018)
} 
Bank Mandiri menetapkan collection fee sebagai berikut:

1) Valuta Rupiah dalam negeri, inkaso keluar dibayar dengan besaran per warkat $\mathrm{Rp}$ 3.000,- untuk nasabah dan Rp 10.000,- untuk non nasabah. Biaya pengiriman Rp 10.000,- per amplop per kota tujuan dan inkaso titipan bank lain Rp 25.000,- per warkat.

2) Valuta Rupiah luar negeri dikenakan biaya komisi 1/16\% Min USD 10 Max USD 50 per warkat, handling charges USD 30. Biaya bank koresponden sesuai dengan biaya yang dikenakan oleh bank koresponden.

Di bank syariah, bank hanya penerima amanat dan mewakili (wakalah) nasabah, bila terjadi kesalahan/keterlambatan hasil inkaso maka bank tidak bertanggung jawab ${ }^{19}$. Di bank konvensional, collection fee untuk valuta Rupiah dalam negeri dapat diterima karena bersifat tetap per warkatnya. Untuk valuta Rupiah luar negeri, penjelasannya sama dengan komisi transfer valas di atas, yaitu:

a. Bank telah memperhitungan beban operasional minimal untuk mengeksekusi transaksi inkaso adalah USD 10. Bank tidak lagi mengenakan komisi lebih dari USD 50 bila money collection lebih dari USD 40.000. Kedua angka ini tetap sehingga dapat dibenarkan bila disandarkan pada fatwa DSN MUI.

b. Bank akan mengenakan fee berdasarkan prosentase bila money collection di antara USD 8.000 hingga USD 40.000. Pengenaan fee berdasarkan prosentase bertentangan dengan fatwa DSN MUI. Agar dapat memenuhi fatwa DSN MUI, maka angka fee-nya diketahui secara pasti dan disepakati oleh kedua pihak. Penggunaan jasa money collection di bank konvensional seyogyanya setelah tidak mendapatkan layanan jasa ini di bank syariah.

\section{Auto Debit atau Standing Instruction}

Auto debit atau standing instruction yaitu perintah kepada bank untuk membayar tagihan secara rutin dengan mendebit rekening tabungan atau giro, misalnya tagihan PLN, telepon, internet, PDAM, pembayaran gaji karyawan perusahaan dll. Bank Mandiri menetapkan fee sebesar Rp 3.000,- per transaksi. Di bank syariah, akad yang berlaku adalah wakalah dan fee dinggap ujrah. Jika fee bersifat tetap, maka fee di bank

\footnotetext{
${ }^{19} \mathrm{https}$ ://www.syariahmandiri.co.id/consumer-banking/jasa-operasional/bsm-inkaso (diakses 2 Oktober 2018)
} 
konvensional dapat juga dianggap ujrah sehingga produk jasa ini halal. Auto debit atau standing instruction saat ini dapat berupa:

a) Payment point, yaitu penerimaan pembayaran tagihan PLN, telepon, internet, PDAM, pajak dengan setoran tunai di teller bank, atau melalui ATM dan internet banking. Bank Mandiri menetapkan fee per transaksi Rp 2.000,- untuk transaksi payment point.

Penjelasan hukum untuk jasa payment point sama dengan auto debit atau standing instruction sehingga produk jasa ini di bank konvesional adalah halal.

b) Debit card yaitu kartu yang akan mengurangi saldo nasabah bila digunakan untuk menarik dana di ATM atau melakukan transaksi non tunai baik di ATM, mesin EDC, dll. Bank Mandiri ${ }^{20}$ dan BCA menetapkan biaya tetap per bulan untuk administrasi kartu debit sebesar 1.500,- untuk jenis silver/classic, Rp 4.000,- untuk jenis gold dan $\mathrm{Rp}$ 6.500,- untuk jenis platinum serta biaya setiap transaksi dengan menggunakan kartu debit dengan tarif sesuai ketentuan.. Bank tidak mengenakan biaya untuk informasi saldo dan penarikan tunai. Inovasi atas debit card berbeda di setiap bank, misalnya Mandiri e-money, BCA Flazz, Mandiri e-toll.

Di bank syariah, akad penggunaan kartu debit adalah ijarah dan biaya bulanan yang dikenakan dianggap ujrah. Transaksi yang terjadi melalui debit card menggunakan akad wakalah bil ujrah.

Di bank konvensional, pengenaan fee untuk penggunaan kartu dan beban fee untuk masing-masing transaksi adalah halal karena fee bersifat tetap dan tidak dikaitkan dengan prosentase dana yang ditransaksikan. Disarankan agar fee per transaksi diketahui oleh nasabah agar tidak merasa dirugikan.

c) E-Banking, SMS Banking dan Phone Banking.

Transaksi pembayaran, transfer dana antar rekening yang dilakukan melalui debit card, dapat juga dilakukan melalui internet banking, sms banking dan phone banking. Fee per transaksi bersifat tetap dan telah diumumkan di situs resmi Bank Mandiri atau BCA.

Penjelasan fikih muamalah untuk jasa ini sama dengan debit card. Hanya saja, nasabah tidak mungkin akan memiliki debit card, e-banking, sms banking dan phone banking, bila nasabah tidak memiliki rekening di bank konvensional. Bila produk sejenis ada di

\footnotetext{
${ }^{20} \mathrm{https} / /$ www.bankmandiri.co.id/web/guest/tarif-layanan\#tarif-produk-kartu (diakses 2 Oktober 2018)
} 
bank syariah, penyimpanan dana di bank konvensional agar dihindari. Bila keadaan terpaksa membuka rekening dan menyimpan dana maka saldo dana yang disisakan hendaknya hanya sekedar saldo minimal saja.

\section{Financing Related Service}

Financing related service merupakan jasa yang dilakukan bank berkaitan dengan penyaluran dana pihak ketiga berupa pembiayaan dalam bentuk:

\section{Bank Garansi}

Bank Guarantee atau Bank Garansi, yaitu jaminan bank atas terlaksananya kewajiban nasabah kepada counter party yang mana counter party selaku Beneficiary akan mendapatkan ganti rugi apabila terjadi wan prestasi atau cidera janji. Bank garansi dapat berbentuk bid bond (garansi selama tender), advance payment bond, performance bond, garansi pembayaran, custom bond, bank garansi jaminan kredit, dll ${ }^{21}$.

Di bank konvensional, komisi yang dipungut adalah $1 \%$ bila nasabah menjaminkan dananya (giro, deposito atau tabungan) di bank sebesar 100\% dari nilai bank garansi dan $2 \%$ bila dana yang dijaminkan kurang dari $100 \%$, ditambah biaya administrasi yang sebesar Rp 250.000. di Bank BCA, komisi yang dikenakan adalah 3\% p.a. Di bank syariah, akad untuk bank garansi adalah kafalah bil ujrah dengan ketentuan ujrah ditetapkan di awal dan tidak berdasarkan prosentase dana. Dengan demikian, fee bank garansi di bank konvensional tidak sesuai dengan prinsip syariah.

\section{Letter of Credit (L/C)}

Letter of Credit (L/C), yaitu suatu janji tertulis bank yang bersifat irrevocable yang diterbitkan atas permintaan pemohon untuk membayar kepada beneficiary atau bank yang mewakili beneficiary untuk melakukan penagihan, apabila dokumen yang diserahkan telah sesuai/comply with dengan persyaratan dokumen yang tercantum dalam $\mathrm{LC}^{22}$. Bank konvensional di dalam negeri dapat menerima pembukaan $\mathrm{L} / \mathrm{C}$ ataupun bertindak sebagai advising/paying bank dari L/C impor yang diterbitkan oleh bank asing. L/C lokal disebut juga dengan Surat Kredit Berdokumen Dalam Negeri (SKBDN). SKBDN dipergunakan

\footnotetext{
${ }^{21} \mathrm{https}$ ://www.bankmandiri.co.id/web/guest/bank-garansi?inheritRedirect=true (diakses 2 Oktober 2018)

${ }^{22}$ ibid (diakses 2 Oktober 2018)
} 


\section{Jurnal Asy-Syukriyyah}

untuk mendukung transaksi perdagangan di dalam negeri. Bank dapat melayani kebutuhan, baik dari sisi Pembeli (Buyer) maupun Penjual (Seller) ${ }^{23}$. Jaminan atas L/C dan SKBDN biasanya adalah dana nasabah di tabungan atau giro yang diblokir selama masa berlaku SKBDN. Komisi standby L/C di bank BCA adalah 3\% p.a dan biaya penerusan Rp $500.000,-$.

Di bank syariah, akad untuk L/C adalah wakalah bil ujrah dengan ketentuan ujrah disepakati di awal dan dinyatakan dalam bentuk nominal, bukan dalam bentuk prosentase $^{24}$. Dengan demikian, L/C di bank konvensional tidak sesuai dengan prinsip syariah. Karena alasan yang darurat seperti tidak adanya bank syariah yang memiliki reputasi di negara yang dituju dan tidak memiliki bank koresponden di luar negeri sehingga L/C tidak dapat dibuka maka penggunaan jasa bank konvensional diperbolehkan sebagai solusi atas keadaan darurat.

\section{Foreign Exchange}

Foreign Exchange, yaitu layanan transaksi penukaran valuta asing, baik telegraphic transfer (TT) ataupun bank notes (devisa tunai) dengan kurs yang ditetapkan oleh bagian treasury bank sesuai perkembangan pasar uang. Nasabah dapat menukar simpanan mata uang Rupiah ke mata uang asing atau menarik simpanan mata uang asing seperti USD dalam bentuk bank note (uang kertas). Kurs yang dipakai adalah kurs beli (buying rate), pada saat bank membeli valas dari nasabah dan kurs jual (selling rate) pada saat bank menjual valas kepada nasabah.

Kalangan bank mengelompokkan bank note menjadi bank note kuat dan bank note lemah. Bank note kuat lebih mudah diperjualbelikan, nilai tukarnya stabil dan frekuensi penjualannya lebih sering terjadi. Bank note lemah sebaliknya. Contoh bank note kuat yaitu USD, SGD, GBP, AUD, JPY, EURO, dan contoh bank note lemah yaitu SAR, PHP, NZD, MYR, THB, dll.

Di bank syariah, akad foreign exchange adalah sharf (jual beli mata uang). Fatwa DSN MUI membolehkan transaksi jual beli mata uang dengan ketentuan sebagai berikut ${ }^{25}$ :

a. Tidak untuk spekulasi (untung-untungan).

\footnotetext{
${ }^{23} \mathrm{https} / / /$ www.bankmandiri.co.id/web/guest/skbdn?inheritRedirect=true (diakses 2 Oktober 2018)

${ }^{24}$ Fatwa DSN MUI No. 34/DSN-MUI/IX/2002 Tentang Letter Of Credit (L/C) Impor Syari'ah

${ }^{25}$ Fatwa DSN MUI No: 28/DSN-MUI/III/2002 Tentang Jual Beli Mata Uang Asing (Sharf)
} 
b. Ada kebutuhan transaksi atau untuk berjaga-jaga (simpanan).

c. Apabila transaksi dilakukan terhadap mata uang sejenis maka nilainya harus sama dan secara tunai (at-taqabudh).

d. Apabila berlainan jenis maka harus dilakukan dengan nilai tukar (kurs) yang berlaku pada saat transaksi dilakukan dan secara tunai.

Di bank konvensional, transaksi valas menggunakan nilai tukar yang berlaku saat transaksi dan kontan. Dengan demikian, transaksi foreign exchange di bank konvensional adalah mubah berdasarkan prinsip syariah.

\section{Credit Card}

Credit Card, yaitu kartu yang digunakan di menarik dana tunai di ATM atau melunasi tagihan pembelian barang/jasa di merchant (toko, dll) sebagai pinjaman/kredit bank dengan limit yang disetujui oleh bank. Pemilik kartu harus melunasi pinjaman dalam 30 hari untuk menghindari bunga atau denda. DSN MUI telah mengeluarkan fatwa No. 42/DSN-MUI/V/2004 perihal Syariah Charge Card, yang mana ketentuan fee yang diperbolehkan yaitu iuran keanggotaan dan ujrah (merchant fee) sama dengan bank konvensional.

Penulis berpendapat bahwa perilaku konsumtif pemegang credit card dapat menjemuskan yang bersangkutan dalam riba yang berlipat-lipat (adh-'afan mudha'afan). Syaikh Muhammad Shalih Al-Munajjid berpendapat haram menggunakan kartu kredit karena beberapa alasan ${ }^{26}$, yaitu: (1) bahwa seorang yang memiliki kartu kredit telah melakukan perjanjian untuk membayar bunga jika terlambat melunasi. Beliau mengutip fatwa Syaikh Al-Utsaimin bahwa perjanjian untuk melakukan riba ini tidak diperbolehkan $^{27}$. (2) Iuran keanggotaan yang nilainya melebihi batas wajar merupakan bagian dari bunga. Dipakai atau tidak kartu tersebut, iuran keanggotaan tetap hangus.

Penulis berpendapat bahwa ketidakmampuan pengguna kartu kredit akan menjerumuskan dirinya ke dalam riba nasi'ah. Karenanya, penggunaan credit card di bank konvesional hukumnya haram.

\footnotetext{
${ }^{26} \mathrm{https}: / /$ islamqa.info/en/13725 (diakses 3 Oktober 2018)

27 https://islamqa.info/en/13735 (diakses 3 Oktober 2018)
} 


\section{Safe Deposit Box}

Safe Deposit Box, yaitu jasa penyewaan kotak penyimpanan harta atau surat-surat berharga yang dirancang secara khusus dari bahan baja dan ditempatkan dalam ruang khasanah yang kokoh, tahan bongkar dan tahan api untuk memberikan rasa aman bagi penggunanya. ${ }^{28}$ Barang yang disimpan dapat berupa sertifikat deposito, sertifikat tanah, saham, obligasi, akte kelahiran, srt nikah, paspor atau benda berharga seperti emas, mutiara, berlian, dll. Biaya jasa dapat dikenakan 2 macam:

1) Biaya sewa yang besarnya tergantung ukuran box yang diinginkan serta jangka waktu sewa, biasanya dibayar per tahun.

2) Setoran Jaminan, merupakan biaya pengganti, apabila kunci yang dipegang oleh nasabah hilang dan box harus dibongkar.

Di Bank Mandiri, biaya sewa ukuran Mini ( 3 s/d 5 inch x 5 inch x 24 inch) adalah Rp 200.000,-, ukuran kecil (3 inch x 10 inch x 24 inch) Rp 500.000,- dan ukuran Besar (10 inch x 10 inch $x 24$ inch) Rp 1.000.000,- dengan uang jaminan kunci Rp 750.000,-.

Di bank syariah, akad penyewaan safe deposit box adalah ijarah dengan ketentuan bahwa barang-barang yang dapat disimpan dalam SDB adalah barang yang berharga yang tidak diharamkan dan tidak dilarang oleh negara ${ }^{29}$. Dengan demikian, penyewaan SDB dan fee yang dikenakan di bank konvensional adalah mubah.

\section{Bank reference atau referensi bank}

Bank reference atau referensi bank, yaitu surat dari bank yang mengkonfirmasi kepemilikan rekening nasabah di bank tersebut, dan juga menjelaskan hubungan baik antara bank dengan nasabah, jenis rekening, tanggal pembukaan. Referensi bank ditandatangani oleh penjabat bank dan dibuat atas permintaan nasabah ketika ingin menjalin kerja sama bisnis dengan pihak yang belum dikenal, baik di dalam maupun luar negeri. Bank Mandiri mengenakan biaya sebesar Rp 50.000,- per satu surat baik redaksi dalam bahasa Indonesia maupun bahasa Inggris ${ }^{30}$.

Pembuatan bank referensi dapat dibenarkan bila nasabah bank syariah hanya memerlukan surat tersebut sebagai surat keterangan yang menyatakan baiknya reputasi

\footnotetext{
${ }^{28} \mathrm{https}$ ://www.bankmandiri.co.id/web/guest/tarif-layanan\#tarif-safe-deposit-box (diakses 2 Oktober 2018)

${ }^{29}$ Fatwa DSN MUI No. 24/DSN-MUI/III/2002 tentang Safe Deposit Box.

${ }^{30} \mathrm{https}$ ://www.bankmandiri.co.id/web/guest/tarif-layanan\#tarif-penerbitan-surat-referensi-bank (diakses 9

Oktober 2018)
} 
yang bersangkutan selama menjadi nasabah bank konvensional (sebelum pindah ke bank syariah). Biaya pembuatan surat referensi dapat dianggap sebagai ujrah.

\section{Agen penjualan produk berbasis syariah}

Agen penjualan produk berbasis syariah seperti surat berharga sukuk ritel dan asuransi syariah, yang mana bank konvensional mendapatkan fee agen. Dalam fikih, akad yang berlaku adalah wakalah, yaitu perusahaan asuransi atau perusahaan yang mengeluarkan sukuk menunjuk bank konvensional sebagai wakil, dan atas jasa tersebut bank mendapatkan ujrah atau komisi. Dengan demikian, membeli sukuk atau asuransi syariah dibank konvensional dapat dibernarkan secara syariah.

\section{Kesimpulan Dan Saran}

\section{Kesimpulan}

1. Tinjauan fikih muamalah atas produk jasa bank konvesional adalah sebagai berikut:

a. Jasa yang berkaitan dengan funding atau penghimpunan dana berupa:

1) Money transfer akadnya adalah wakalah dan biaya transfer adalah ujrah.

2) Money collection atau inkaso yang mana bank sebagai penerima amanat dan mewakili (wakalah) nasabah untuk menagih maka akadnya adalah wakalah. Biaya money collection merupakan ujrah.

3) Auto debit atau standing instruction akadnya juga wakalah dan biaya audit debit merupakan ujrah.

b. Jasa yang berkaitan dengan financing atau pembiayaan berupa:

1) Bank garansi akadnya adalah kafalah. Namun karena fee atau komisi bank garansi berdasarkan prosentase dari dana yang tercantum dalam surat jaminan maka tidak sesuai dengan syariah.

2) Letter of Credit prinsip pengenaan fee-nya sama dengan bank garansi, yaitu prosentasi tertentu dari dana LC maka LC di bank konvensional tidak sesuai dengan ketentuan syariah.

3) Foreign Exchange akadnya adalah sharf berdasarkan kurs yang disepakati kedua pihak. Dengan demikian, foreign exhchange atau jasa penukaran uang di bank konvensional dibolehkan.

4) Credit Card di bank konvensional dikenakan bunga atas keterlambatan pelunasan dan mengakibatkan riba yang berlipat-lipat. Nasabah yang 


\section{Jurnal Asy-Syukriyyah}

melalakukan akad credit card juga dianggap telah mengikatkan dirinya untuk jatuh dalam transaksi riba. Untuk itu, credit card di bank konvensional tidak sesuai dengan syariah.

5) Safe Deposit Box dibolekan karena hanya menitipkan barang di tempat yang aman dan akadnya adalah ijarah. Fee atas penyewaannya dianggap ujroh.

6) Bank reference adalah surat keterangan untuk menyatakan baiknya reputasi seseorang atau badan hukum selama menjadi nasabah. Biaya atas pembuatan surat referensi bank dianggap mubah.

2. Sebagaimana kaidah ushul fikih mengatakan, "Adh-dhorurotu tubiihu al-mahdzuroti" yaitu 'darurat membolehkan yang terlarang', maka dengan adanya bank syariah, hukum bertransaksi di bank konvensional untuk menyimpan, meminjam dan menggunakan produk jasa tidak lagi 'darurat'. Menyimpan dan meminjam dana di bank konvensional tidak lepas dari imbalan jasa yang dihitung berdasarkan tingkat suku bunga. Imbalan jasa tersebut dihukumi riba yang diharamkan. Bila fee/komisi diketahui dan disetujui oleh nasabah dan bank di awal transaksi dengan besaran yang tetap dan pasti serta dinyatakan dalam bentuk nominal bukan prosentase atas pokok dana yang ditransaksikan maka produk jasa di bank konvensional tersebut mubah.

\section{Saran}

1. Masyarakat muslim perlu memahami bahwa produk jasa bank konvensional yang imbalan jasanya berupa komisi/fee/ujrah yang tetap dan tidak berdasarkan perhitungan persentasi dana masih halal untuk digunakan. Namun sekiranya bank syariah menyediakan layanan serupa, maka menggunakan jasa bank syariah lebih utama daripada jasa bank konvensional.

2. Perlu peran ulama dan akademisi ekonomi Islam untuk memberi penjelasan agar bank syariah lebih diminati oleh masyarakat muslim.

3. Dengan mempertimbangkan fikih muamalah, bank syariah diharapkan menyediakan produk mirror agar dilirik oleh masyarakat muslim yang memerlukan jasa sejenis yang hanya ada di bank konvesional. 


\section{DAFTAR PUSTAKA}

Azmatkhan, Shohibul Faroji. (2014). The Return of Dinar Dirham. Jakarta: PT Khalifa Femark Nusantara.

Isa, Siti Sarah Mat; Ma'in, Masturah; Hanif, Azlina. Islamic Bank's Fee Income and Risk: Evidence from Malaysia. (Selangor Malaysia:Universiti Teknologi MARA(UiTM), 2016.

Mardani, Fikih Ekonomi Syariah, (Jakarta: Penerbit Kencana Prenadamedia Group, 2012).

Mardani, Hukum Ekonomi Syariah di Indonesia, (Jakarta : PT Refika Editama, 2011).

Mardani, Hukum Perikatan Syariah di Indonesia, (Jakarta : Sinar Grafika, 2013).

Fatwa DSN MUI No. 09/DSN-MUI/IV/2000 Tentang Pembiayaan Ijarah.

Fatwa DSN MUI No. 10/DSN-MUI/IV/2000 Tentang Wakalah.

Fatwa DSN MUI No. 11/DSN-MUI/IV/2000 Tentang Kafalah.

Fatwa DSN MUI No. 12/DSN-MUI/IV/2000 Tentang Hawalah.

Fatwa DSN MUI No. 22/DSN-MUI/III/2002Tentang Safe Deposit Box.

Fatwa DSN MUI No. 24/DSN-MUI/III/2002Tentang Jual Beli Mata Uang (Al-Sharf).

Fatwa DSN MUI No. 34/DSN-MUI/IX/2002 Tentang Letter Of Credit (L/C) Impor Syari'ah.

Fatwa DSN MUI No. 35/DSN-MUI/IX/2002 Tentang Letter Of Credit (L/C) Ekspor Syari'ah.

Fatwa DSN MUI No. 42/DSN-MUI/V/2004 Tentang Syariah Charge Card.

Fatwa DSN MUI No. 54/DSN-MUI/X/2006 Tentang Syariah Card.

Fatwa DSN MUI No. 57/DSN-MUI/V/2007 Tentang Letter Of Credit (L/C) Dengan Akad Kafalah Bil Ujrah.

Fatwa DSN MUI No. 58/DSN-MUI/V/2007 Tentang Hawalah Bil Ujrah.

Lainnya:

Zainul Arifin, slide mata kuliah Keuangan dan Perbankan Islam IEF Trisakti Jakarta, 2014. 